\title{
KETERKAITAN ANTARA MODUL BEBAS DENGAN MODUL DILIHAT DARI SIFAT-SIFAT HOMOMORFISME MODUL
}

\author{
Khusnul Afifa1, Abdussakir ${ }^{2}$ \\ ${ }_{1}^{1}$ Mahasiswa Jurusan Matematika UIN Maulana Malik Ibrahim Malang \\ ${ }^{2}$ Dosen Jurusan Matematika UIN Maulana Malik Ibrahim Malang \\ e-mail: apheecute@gmail.com, abdussakir@gmail.com
}

\begin{abstract}
ABSTRAK
Dalam artikel ini akan dibahas tentang cara untuk mengetahui suatu $R$-modul adalah modul bebas atau bukan dengan memanfaatkan suatu modul bebas sebagai $R$-modul melalui media homomorfisma modul. Penelitian ini menggunakan metode kajian kepustakaan (library research), yaitu melakukan penelitian untuk memperoleh data-data dan informasi serta objek yang digunakan dalam pembahasan masalah tersebut. Berdasarkan pembahasan dapat diperoleh bahwa suatu $R$-modul merupakan modul bebas jika $R$-modul tersebut isomorfik dengan suatu modul bebas sebagai $R$-modul. Artinya, suatu $R$ modul merupakan modul bebas jika terdapat suatu isomorfisma dari $R$-modul tersebut ke suatu modul bebas yang juga merupakan suatu $R$-modul. Lebih jauh lagi, jika suatu $R$-modul adalah modul bebas, maka $R$-modul tersebut isomorfik dengan $R^{n}$, dimana $n$ adalah kardinalitas dari basis bagi $R$-modul tersebut.
\end{abstract}

Kata Kunci : basis, homomorfisme modul, modul, modul bebas, Ring

\section{ABSTRACT}

In this paper, the way to know whether $R$-module is free module or not will be discussed by using free module as $R$-module through module homomorphism media. In this research, the author used library research, which is conducting the research to obtain data and information about object that used in the discussion. Based on the discussion, it was obtained that $R$-module was free module if the $R$-module was isomorphic to free module as $R$-module. It means that $R$-module was free module if there is isomorphism from the $R$-module to the free module which is an $R$-module. Furthermore, if an $R$-module was free module, then the $R$-module would be isomorphic with $R^{n}$, where $n$ is cardinality from basis for the $R$ module.

Keywords: basis, free module, module, module homomorphism, ring.

\section{PENDAHULUAN}

Struktur aljabar yang dikembangkan dalam dua himpunan yang tidak kosong dengan dua operasi biner dan memenuhi syarat tertentu, yaitu distributif kanan, distributif kiri, assosiatif, dan mempunyai elemen identitas disebut dengan modul [1].

Modul sendiri juga dapat dikembangkan menjadi beberapa sub pembahasan di antaranya adalah homomorfisme. Seperti halnya ring di dalamnya dibahas mengenai homomorfisme ring, maka di dalam modul juga dibahas mengenai homomorfisme modul. Homomorfisme modul merupakan suatu pemetaan dari suatu modul $M$ ke modul $N$ yang mengawetkan kedua operasi yang ada dalam modul. Homomorfisme modul dibedakan menjadi 3, yaitu homomorfisme yang merupakan pemetaan satu-satu (one to one/ injektif) disebut monomorfisme modul, homomorfisme yang merupakan pemetaan pada (onto/surjektif) disebut epimorfisme modul, dan homomorfisme yang mempunyai sifat keduaduanya (injektif dan surjektif) atau yang dikenal dengan istilah bijektif disebut isomorfisme modul [2].

Suatu modul yang memiliki basis atau himpunan pembangun disebut modul bebas. Jika $M$ adalah $R$-modul dan terdapat $X \subseteq M$ dengan $X$ merupakan basis untuk $M$, maka $M$ disebut modul bebas [3].

Penelitian ini dilakukan untuk mengetahui suatu $R$-modul adalah modul bebas atau bukan dengan memanfaatkan suatu modul bebas sebagai $R$-modul melalui media homomorfisme modul. 


\section{TEORI DASAR}

\section{Fungsi}

Suatu fungsi dari himpunan $S$ ke $T$ adalah aturan yang mengaitkan setiap anggota $S$ dengan tepat satu anggota $T$. Anggota $S$ disebut domain dari fungsi, dan himpunan $T$ disebut kodomain [4].

\section{Operasi Biner}

Operasi + pada suatu himpunan tidak kosong $G$ adalah biner jika dan hanya jika $a \in$ $G, b \in G \quad$ maka $a+b \in G, \forall a, b \in G$. Sifat tersebut dari operasi di $G$ dikatakan tertutup dan jika sifat ini memenuhi operasi + di $G$ [5].

\section{Grup}

Misalkan $G$ adalah suatu himpunan tak kosong dan pada $G$ didefinisikan operasi biner +. Sistem aljabar $(G,+)$ disebut grup jika memenuhi aksioma-aksioma:

a. Operasi + bersifat assosiatif di $G$

$(a+b)+c=a+(b+c), \forall a, b, c \in G$

b. $G$ mempunyai unsur identitas terhadap operasi +

Misalkan $e$ unsur di $G$ sedemikian hingga

$a+e=e+a, \forall a \in G$ maka $e$ disebut unsur identitas.

c. Setiap unsur di $G$ mempunyai invers terhadap operasi +

Untuk setiap $a \in G$ ada $a^{-1} \in G$ yang disebut sebagai invers dari $a$, sehingga $a^{-1}+a=a+$ $a^{-1}=e$, dimana $e$ adalah unsur identitas di $G$ [5].

Grup $(G,+)$ dikatakan grup komutatif jika untuk setiap unsur $a$ dan $b$ di $G$ berlaku $a+b=$ $b+a[6]$

\section{Ring}

$R$ adalah himpunan tak kosong dengan dua operasi biner yang dilambangkan dengan + dan $\times$ (penjumlahan pada operasi pertama dan perkalian pada operasi kedua) disebut ring jika memenuhi syarat-syarat sebagai berikut:

i. $(R,+)$ adalah grup komutatif

ii. Operasi $\times$ bersifat asssosiatif

$$
(a \times b) \times c=a \times(b \times c), \forall a, b, c \in R
$$

iii. Operasi $\times$ bersifat distributif terhadap $+\mathrm{di}$

$R, \forall a, b, c \in R$

$(a+b) \times c=(a \times c)+(b \times c)$

(distributif kanan)

$a(b+c)=(a \times b)+(a \times c)$

(distributif kiri)

[7].

Misalkan $R$ dan $S$ adalah ring. Homomorfisme ring adalah pemetaan $\varphi: R \rightarrow S$ jika memenuhi syarat-syarat berikut: i. $\varphi(a+b)=\varphi(a)+\varphi(b), \forall a, b \in R$

ii. $\varphi(a b)=\varphi(a) \varphi(b), \forall a, b \in R$ [7].

\section{Modul}

Misalkan $(R,+, \times)$ adalah ring. $R$-modul di $R$ adalah himpunan $M$ yang memenuhi:

i. $(M,+)$ adalah grup komutatif

ii. Diberikan pemetaan $R \times M \rightarrow M$, dimana $r m, \forall r \in R, m \in M$ yang memenuhi:

a. Distributif kanan $(r+s) m=r m+s m, \forall r, s \in R, m \in M$

b. Distributif kiri $r(m+n)=r m+r n, \forall r \in R, m, n \in M$

c. Assosiatif $(r s) m=r(s m), \forall r, s \in R, m \in M$

Jika R mempunyai unsur identitas 1 maka d. $1 m=m, \forall m \in M[7]$.

Misal $R$ adalah ring dan $M$ adalah $R$ modul. $R$-submodul di $R$ adalah $N$ subgrup dari $M$ yang bersifat tertutup terhadap elemenelemen ring, yaitu $r n \in N, \forall r \in R, n \in N$ [7].

\section{Teorema 1}

Misalkan $R$ adalah ring dan $M$ adalah $R$ modul. Subset $N$ di $M$ adalah submodul di $M$ jika dan hanya jika:
a. $N \neq \emptyset$
b. $x+\alpha y \in N, \forall \alpha \in R, \forall x, y \in N$ [7].

\section{Bukti}

a. Jika $N$ adalah submodul di $M$ maka $0 \in N$ jadi $N \neq \varnothing$.

b. $N$ bersifat tertutup terhadap operasi penjumlahan

Misal $\alpha=-1$, maka

$$
\begin{aligned}
x+(-1) y & =x+(-y) \\
& =x-y \in N
\end{aligned}
$$

Maka $x+\alpha y \in N, \forall \alpha \in R, \forall x, y \in N$.

Misalkan $R$ adalah ring dan misalkan $M$ dan $N$ adalah $R$-modul. Pemetaan $\varphi: M \rightarrow N$ disebut homomorfisme modul jika pemetaan itu memenuhi syarat sebagai berikut:

a) $\varphi(x+y)=\varphi(x)+\varphi(y), \forall x, y \in M$

b) $\varphi(\alpha x)=\alpha \varphi(x), \forall \alpha \in R, x \in M$ [7].

\section{Modul Bebas}

Diketahui $M$ adalah $R$-modul. Jika terdapat $X \subseteq M$ dengan $X$ merupakan basis untuk $M$, maka $M$ disebut modul bebas [3].

Misalkan $M$ suatu R-modul dan $X \subseteq M$. Unsur $y \in M$ dikatakan kombinasi linier dari $X$ jika untuk semua $x \in X$ dapat diungkapkan dalam bentuk

$$
y=\alpha_{1} x_{1}+\alpha_{2} x_{2}+\cdots+\alpha_{n} x_{n}
$$

dimana $\alpha_{1}, \alpha_{2}, \ldots, \alpha_{n}$ adalah skalar [8].

Misalkan $M$ suatu R-modul dan $X \subseteq M$.

Jika untuk semua $x \in X$ dapat dinyatakan 
sebagai kombinasi linier maka dikatakan bahwa $X$ merentang $M[\mathbf{8}]$.

Misalkan $M$ suatu R-modul dan $X \subseteq M$. Maka persamaan

$$
\alpha_{1} x_{1}+\alpha_{2} x_{2}+\cdots+\alpha_{n} x_{n}=0
$$

Mempunyai paling sedikit satu pemecahan, yakni

$$
\alpha_{1}=0, \alpha_{2}=0, \ldots, \alpha_{n}=0
$$

Jika ini adalah satu-satunya pemecahan, maka $X$ dinamakan himpunan bebas linier. Jika ada pemecahan lain, maka $S$ dinamakan himpunan tak bebas linier [8].

Diketahui $M$ adalah $R$-modul dan $X \subseteq M$. Himpunan $X$ dikatakan basis untuk $M$ jika dan hanya jika:
a. $X$ merentang $M$
b. $X$ bebas linier [8].

\section{METODE PENELITIAN}

Metode yang digunakan dalam penelitian ini adalah metode penelitian kepustakaan (library research). Adapun langkah-langkah yang akan digunakan oleh peneliti dalam membahas penelitian ini adalah:

1. Mendefinisikan kembali tentang modul, modul bebas, dan homomorfisme modul serta membuat contohnya dan contoh yang salah

2. Mendefinisikan monomorfisme modul, epimorfisme modul, dan isomorfisme modul

3. Membuat contoh dan contoh yang salah dari monomorfisme modul, epimorfisme modul, dan isomorfisme modul dengan menggunakan domain modul bebas dan kodomainnya modul

4. Dari poin 3 didapatkan dua teorema baru dan membuktikan teorema tersebut serta memberikan contohnya.

\section{PEMBAHASAN}

Homomorfisme modul merupakan pemetaan dari suatu modul ke modul yang lain yang mengawetkan kedua operasi yang ada dalam modul tersebut.

Misalkan $R$ adalah ring dan misalkan $M$ dan $N$ adalah $R$-modul. Pemetaan $\varphi: M \rightarrow N$ disebut homomorfisme modul jika pemetaan itu memenuhi syarat sebagai berikut:

a) $\varphi(x+y)=\varphi(x)+\varphi(y), \forall x, y \in M$

b) $\varphi(\alpha x)=\alpha \varphi(x), \forall \alpha \in R, x \in M[7]$.

Contoh:

Diberikan $R$ dan $R^{2}$ sebagai $R$-modul. Melalui pemetaan $\varphi: R^{2} \rightarrow R$ yang didefinisikan dengan $\varphi(x)=0_{R}$. Akan ditunjukkan $\varphi$ adalah homomorfisme modul.
Berdasarkan definisi homomorfisme modul, $\varphi$ dikatakan homomorfisme modul jika memenuhi sifat-sifat berikut:

i. $\varphi(x+y)=\varphi(x)+\varphi(y)$

$\varphi(x+y)=0_{R} \quad($ berdasarkan definisi $\varphi$, karena $x+y \in R^{2}$ )

Dilain pihak,

$\varphi(x)+\varphi(y)=0_{R}+0_{R}=0_{R}$

Jadi $\varphi(x+y)=\varphi(x)+\varphi(y)$

ii. $\varphi(\alpha x)=\alpha \varphi(x)$

$\varphi(\alpha y)=0_{R}($ berdasarkan definisi $\varphi$, karena $\alpha y \in R^{2}$ )

Dilain pihak,

$\alpha \varphi(y)=\alpha 0_{R}=0_{R}$

$\varphi(\alpha x)=\alpha \varphi(x)$

Jadi $\varphi$ terbukti homomorfisme modul.

Secara garis besar, homomorfisme modul dibedakan menjadi tiga, yaitu monomorfisme, epimorfisme, dan isomorfisme.

Misalkan $R$ adalah ring, $M$ dan $N$ adalah $R$ -modul, jika homomorfisme modul dari $M$ ke $N$ bersifat injektif (satu-satu) maka disebut monomorfisme modul [7].

Contoh:

Diberikan $Z$ dan $Z \times Z_{2}$ sebagai $Z$-modul. Pemetaan $\varphi: Z \rightarrow Z \times Z_{2}$ didefinisikan sebagai $\varphi(x)=(x, 0)$. Pemetaan $\varphi$ ini adalah pemetaan monomorfisme.

Ambil sebarang $x, y \in Z$ dan $\alpha \in Z$, maka

1. $\varphi(x+y)=(x+y, 0)=(x, 0)+(y, 0)=$ $\varphi(x)+\varphi(y)$

2. $\varphi(\alpha x)=(\alpha x, 0)=(\alpha x, \alpha 0)=\alpha(x, 0)=$ $\alpha \varphi(x)$

Dari 1 dan 2, dapat disimpulkan bahwa $\varphi$ adalah suatu homomorfisme modul. Kemudian, untuk sebarang $\varphi(x), \varphi(y) \in R_{\varphi}$ dengan $\varphi(x)=\varphi(y)$, berlaku

$\mathbf{0}=\varphi(x)-\varphi(y)=(x, 0)-(y, 0)=(x-y, 0)$

Oleh karena itu, $x-y=0$. Dengan kata lain $x=$ $y$. Jadi $\varphi$ adalah pemetaan 1-1.

Dilain pihak, terdapat $(1,1) \in Z x Z_{2}$ Sehingga $(1,1) \neq \varphi(x)$ untuk setiap $x \in Z$. Jadi $\varphi$ bukan pemetaan pada.

Jadi dapat disimpulkan bahwa $\varphi$ adalah monomorfisme modul.

Misal $R$ adalah ring, $M$ dan $N$ adalah $R$ modul, jika homomorfisme modul dari $M$ ke $N$ bersifat surjektif (pada/onto), maka disebut epimorfisme modul [7].

Contoh:

Diberikan $Z$ dan $Z_{2}$ sebagai $Z$-modul. Pemetaan $\varphi: Z \rightarrow Z_{2}$ didefinisikan sebagai $\varphi(x)=$ $x(\bmod 2)$. Pemetaan $\varphi$ ini adalah pemetaan epimorfisme.

Ambil sebarang $x, y \in Z$ dan $\alpha \in Z$, maka

1. $\varphi(x+y)=x+y(\bmod 2)=x(\bmod 2)+$ $y(\bmod 2)=\varphi(x)+\varphi(y)$ 
2. $\varphi(\alpha x)=\alpha x(\bmod 2)=\alpha(x(\bmod 2))=$ $\alpha \varphi(x)$

Dari 1 dan 2, dapat disimpulkan bahwa $\varphi$ adalah suatu homomorfisme modul. Kemudian, untuk sebarang $z \in Z_{2}$, maka

i) Untuk $z=0$, maka terdapat $0 \in Z$ sehingga $\varphi(0)=0$

ii) Untuk $z=1$, maka terdapat $3 \in Z$ sehingga $\varphi(3)=1$

Jadi $\varphi$ adalah pemetaan pada.

Dilain pihak, terdapat $1,3 \in Z$ dengan $1 \neq 3$, tetapi $\varphi(3)=1=\varphi(1)$. Jadi $\varphi$ bukan pemetaan $1-1$.

Jadi dapat disimpulkan bahwa $\varphi$ adalah epimorfisme modul.

Misalkan $R$ adalah ring, $M$ dan $N$ adalah $R$-modul, jika homomorfisme modul dari $M$ ke $N$ bersifat bijektif (satu-satu) dan surjektif (pada), dengan kata lain homomorfisme modul dari $M$ ke $N$ bersifat bijektif, maka disebut isomorfisme modul. Jika terdapat suatu isomorfisme dari $M$ ke $N$, maka $M$ isomorfik dengan $N$ atau $N$ isomorfik dengan $M$ [7].

Contoh:

Diberikan $Z^{4}$ dan $\quad M=$ $\left\{\left(\begin{array}{ll}a_{11} & a_{12} \\ a_{21} & a_{22}\end{array}\right) \mid a_{11}, a_{12}, a_{21}, a_{22} \in Z\right\}$ adalah $Z$ modul. Pemetaan $\varphi: M \rightarrow Z^{4}$ didefinisikan sebagai $\varphi(a)=\left(a_{11}, a_{12}, a_{21}, a_{22}\right)$ dimana $a=$ $\left(\begin{array}{ll}a_{11} & a_{12} \\ a_{21} & a_{22}\end{array}\right)$. Pemetaan $\varphi$ ini adalah pemetaan isomorfisme.

Ambil sebarang $x, y \in M$ dan $\alpha \in \mathbb{Z}$, maka

$$
\text { i) } \begin{aligned}
\varphi(x+y)= & \left(\begin{array}{ll}
x_{11}+y_{11} & x_{12}+y_{12} \\
x_{21}+y_{21} & x_{22}+y_{22}
\end{array}\right) \\
= & \left(x_{11}+y_{11}, x_{12}+y_{12}, x_{21}+\right. \\
& \left.y_{21}, x_{22}+y_{22}\right) \\
= & \left(x_{11}, x_{12}, x_{21}, x_{22}\right)+ \\
& \left(y_{11}, y_{12}, y_{21}, y_{22}\right) \\
= & \varphi(x)+\varphi(y)
\end{aligned}
$$

ii) $\varphi(\alpha x)=\varphi\left(\left(\begin{array}{ll}\alpha x_{11} & \alpha x_{12} \\ \alpha x_{21} & \alpha x_{22}\end{array}\right)\right)$

$$
\begin{aligned}
& =\left(\alpha x_{11}, \alpha x_{12}, \alpha x_{21}, \alpha x_{22}\right) \\
& =\alpha\left(x_{11}, x_{12}, x_{21}, x_{22}\right) \\
& =\alpha \varphi(x)
\end{aligned}
$$

Dari (i) dan (ii), dapat disimpulkan bahwa $\varphi$ adalah suatu homomorfisme modul.

Kemudian untuk sebarang
$\left(m_{11}, m_{12}, m_{21}, m_{22}\right) \in Z$, maka terdapat $m=$ $\left(\begin{array}{ll}m_{11} & m_{12} \\ m_{21} & m_{22}\end{array}\right)$ anggota $M$ sehingga $\varphi(m)=$ $\left(m_{11}, m_{12}, m_{21}, m_{22}\right)$.

Jadi $\varphi$ adalah pemetaan pada.

Di lain pihak, untuk sebarang $\varphi(x), \varphi(y) \in R_{\varphi}$ dengan $\varphi(x)=\varphi(y)$, berlaku

$$
\begin{aligned}
\mathbf{0} & =\varphi(x)-\varphi(y) \\
& =\left(x_{11}, x_{12}, x_{21}, x_{22}\right)-\left(y_{11}, y_{12}, y_{21}, y_{22}\right) \\
& =\left(x_{11}-y_{11}, x_{12}-y_{12}, x_{21}-y_{21}, x_{22}-y_{22}\right)
\end{aligned}
$$

Oleh karena itu, $x_{i j}-y_{i j}=0$ untuk setiap $i, j=1,2$. Dengan kata lain $x_{i j}=y_{i j}$ untuk setiap $i, j=1,2$. Sehingga diperoleh $x=y$. Jadi $\varphi$ adalah pemetaan 1-1.

Jadi dapat disimpulkan bahwa $\varphi$ adalah isomorfisma modul.

Pada contoh monomorfisme dan epimorfisme, domainnya adalah $Z$ sebagai $Z$ modul. Telah diketahui bahwa $Z$ sebagai $Z$ modul adalah Modul bebas dengan basis $\{1\}$. Pada contoh epimorfisme, mudah diketahui bahwa $Z_{2}$ sebagai $Z$-modul bukan modul bebas disebabkan satu-satunya pembangun di $Z_{2}$, yaitu $\{1\}$ tak bebas linear, karena terdapat $2 \in Z$ dimana $2 \neq 0$, berlaku $2 \cdot 1=0$ di $Z_{2}$. Jadi epimorfisme bukan jaminan untuk kodomain merupakan modul bebas saat domain modul bebas. Selanjutnya, pada contoh monomorfisme, $Z \times Z_{2}$ juga bukan modul bebas ( Hal ini akan dibuktikan dengan teorema terakhir pada bab ini ). Jadi monomorfisme bukan jaminan untuk kodomain merupakan modul bebas saat domain modul bebas. Terakhir, pada contoh ketiga, yaitu isomorfisme, $Z^{4}$ sebagai $Z$-modul adalah modul bebas dengan basis $\{(1,1,1,1)\}$. Begitu pula dengan $M$ sebagai $Z$-modul juga merupakan modul bebas dengan basis $\left\{\left(\begin{array}{ll}1 & 0 \\ 0 & 0\end{array}\right),\left(\begin{array}{ll}0 & 1 \\ 0 & 0\end{array}\right),\left(\begin{array}{ll}0 & 0 \\ 1 & 0\end{array}\right),\left(\begin{array}{ll}0 & 0 \\ 0 & 1\end{array}\right)\right\}$. Dari contoh isomorfisme ini, ada kemungkinan bahwa isomorfisme bisa jadi jaminan untuk kodomain modul bebas saat domain adalah modul bebas. Hal ini dijawab oleh teorema berikut.

\section{Teorema 2}

Misalkan $M$ dan $F$ adalah $R$-modul. Jika $M$ adalah modul bebas dan $M$ isomorfik dengan $F$, maka $F$ modul bebas.

\section{Bukti}

Misalkan $X=\left\{x_{1}, x_{2}, \ldots, x_{n}\right\}$ adalah basis untuk $M$ dan $\varphi$ adalah isomorfisme dari $M$ ke $F$. Selanjutnya akan ditunjukkan bahwa $V=$ $\left\{\varphi\left(x_{1}\right), \varphi\left(x_{1}\right), \ldots, \varphi\left(x_{n}\right)\right\}$ adalah basis bagi $F$.

i) $V$ membangun $F$

Ambil $y \in F$. Karena $\varphi$ pemetaan pada, maka terdapat $m \in M$ sehingga $\varphi(m)=y$. Karena $M$ modul bebas, maka terdapat $r_{1}, r_{2}, \ldots, r_{n} \in R$ sehingga

$$
m=\sum_{i=1}^{n} r_{i} x_{i}=r_{1} x_{1}+r_{2} x_{2}+r_{3} x_{3}+\cdots+r_{n} x_{n}
$$

Selain itu, karena $\varphi$ suatu homomorfisme, maka $\varphi(m)=\varphi\left(\sum_{i=1}^{n} r_{i} x_{i}\right)$

$$
\begin{aligned}
& =\varphi\left(r_{1} x_{1}+r_{2} x_{2}+\cdots+r_{n} x_{n}\right) \\
& =\varphi\left(r_{1} x_{1}\right)+\varphi\left(r_{2} x_{2}\right)+\cdots+\varphi\left(r_{n} x_{n}\right) \\
& =r_{1} \varphi\left(x_{1}\right)+r_{2} \varphi\left(x_{2}\right)+\cdots+r_{n} \varphi\left(x_{n}\right) \\
= & \sum_{i=1}^{n} r_{i} \varphi\left(x_{i}\right) \\
= & y
\end{aligned}
$$


Jadi $V$ membangun $F$.

ii) $V$ bebas Linear

Berikutnya, persamaan $\sum_{i=1}^{n} s_{i} \varphi\left(x_{i}\right)=0_{F}$ dimana $s_{1}, s_{2}, \ldots, s_{n} \in R$, dapat dituliskan menjadi $\varphi\left(\sum_{i=1}^{n} s_{i} x_{i}\right)=0_{F}$. Karena $\varphi$ pemetaan 1-1, maka prapeta dari $0_{F}$ adalah $0_{M}$. Dengan kata lain $\sum_{i=1}^{n} s_{i} x_{i}=0_{M}$. Karena $X$ adalah basis bagi $M$, maka persamaan $\sum_{i=1}^{n} s_{i} x_{i}=0_{M}$ hanya dipenuhi oleh $s_{1}=s_{2}=\cdots=s_{n}=0$. Oleh karena itu persamaan $\sum_{i=1}^{n} s_{i} \varphi\left(x_{i}\right)=0_{F}$ hanya dipenuhi oleh skalar $s_{1}=s_{2}=\cdots=s_{n}=0$.

Jadi $V$ bebas linear.

Oleh karena itu, $V$ basis bagi $F$. Jadi $F$ adalah modul bebas.

Teorema di atas adalah jaminan mengetahui suatu modul adalah modul bebas dengan memanfaatkan modul bebas yang lain melalui isomorfisme. Namun, masih diperlukan cara untuk menentukan modul pada domain (atau kodomain ) tersebut modul bebas atau bukan, tentu saja tidak dengan memanfaatkan kebebasan dari modul pada kodomain ( atau domain ) karena tentu saja hal ini seperti berputar ditempat yang sama. Teorema berikut dapat dijadikan sebagai prosedur untuk mengetahui apakah suatu $R$-modul adalah modul bebas atau bukan. Teorema ini menjadi teorema penutup pada bab pembahasan ini.

\section{Teorema 3}

Misalkan $M$ adalah $R$-modul. Jika $M$ adalah modul bebas maka $M$ isomorfik dengan $R^{n}$, dimana $n$ adalah kardinalitas dari basis $M$.

\section{Bukti}

Misalkan $X=\left\{x_{1}, x_{2}, \ldots, x_{n}\right\}$ adalah basis untuk $M$. Maka setiap $m$ di $M$ dapat dituliskan secara tunggal sebagai $m=\sum_{i=1}^{n} m_{i} x_{i}$ untuk suatu $m_{1}, m_{2}, \ldots, m_{n} \in R$. Sekarang, misalkan pemetaan $\varphi: M \rightarrow R^{n}$ didefinisikan sebagai

$$
\varphi(m)=\left(m_{1}, m_{2}, \ldots, m_{n}\right)
$$

dimana $m=\sum_{i=1}^{n} m_{i} x_{i}$ untuk $m_{1}, m_{2}, \ldots, m_{n} \in R$. Ambil sebarang $z, y \in M$ dan $\alpha \in Z$, maka

i) $\varphi(z+y)=\left(\sum_{i=1}^{n}\left(z_{i}+y_{i}\right) x_{i}\right)$

$$
\begin{aligned}
= & \left(z_{1}+y_{1}, z_{2}+y_{2}, z_{3}+y_{3}, \ldots, z_{n}+\right. \\
& \left.y_{n}\right) \\
= & \left(z_{1}, z, \ldots, z_{n}\right)+\left(y_{1}, y_{2}, \ldots, y_{n}\right) \\
= & \varphi(z)+\varphi(y)
\end{aligned}
$$

ii) $\varphi(\alpha y)=\varphi\left(\sum_{i=1}^{n}\left(\alpha y_{i}\right) x_{i}\right)$

$$
\begin{aligned}
& =\left(\alpha y_{1}, \alpha y_{2}, \alpha y_{3}, \ldots, \alpha y_{n}\right) \\
& =\alpha\left(y_{1}, y_{2}, y_{3}, \ldots, y_{n}\right) \\
& =\alpha \varphi(y)
\end{aligned}
$$

Dari (i) dan (ii), dapat disimpulkan bahwa $\varphi$ adalah suatu homomorfisme modul.

$$
\text { Kemudian, untuk sebarang }
$$

$\left(m_{1}, m_{2}, \ldots, m_{n}\right) \in R^{n}$, maka terdapat $m=$ $\sum_{i=1}^{n} m_{i} x_{i}$ anggota $M$ sehingga $\varphi(m)=$ $\left(m_{1}, m_{2}, \ldots, m_{n}\right)$. Jadi $\varphi$ adalah pemetaan pada.
Di lain pihak, untuk sebarang $\varphi(z), \varphi(y) \in R_{\varphi}$ dengan $\varphi(z)=\varphi(y)$, berlaku

$\mathbf{0}=\varphi(z)-\varphi(y)$

$=\left(z_{1}, z_{2}, \ldots, z_{n}\right)-\left(y_{1}, y_{2}, \ldots, y_{n}\right)$

$=\left(z_{1}-y_{1}, z_{2}-y_{2}, z_{3}-y_{3}, \ldots, z_{n}-y_{n}\right)$

Oleh karena itu, $x_{i}-y_{i}=0$ untuk setiap $i=$ $1,2, \ldots, n$, dengan kata lain $x_{i}=y_{i}$ untuk setiap $i=1,2, \ldots, n$. Sehingga diperoleh $z=y$, jadi $\varphi$ adalah pemetaan 1-1.

Jadi dapat disimpulkan bahwa $\varphi$ adalah isomorfisme modul. Oleh karena itu, $M$ isomorfik dengan $R^{n}$.

\section{Akibat dari Teorema 2}

Jika $M$ isomorfik dengan $R^{n}$ dan $M$ adalah modul bebas, maka $R^{n}$ modul bebas.

\section{PENUTUP}

\section{Kesimpulan}

Dari pembahasan pada bab 3, dapat disimpulkan bahwa suatu $R$-modul merupakan modul bebas jika $R$-modul tersebut isomorfik dengan suatu modul bebas sebagai $R$-modul. Artinya, suatu $R$-modul merupakan modul bebas jika terdapat suatu isomorfisme dari $R$-modul tersebut ke suatu modul bebas yang juga merupakan suatu $R$-modul. Lebih jauh lagi, jika suatu $R$-modul adalah modul bebas, maka $R$ modul tersebut isomorfik dengan $R^{n}$, dimana $n$ adalah kardinalitas dari basis bagi $R$-modul tersebut.

\section{Saran}

Dalam studi modul, dikenal pula modul notherian. Untuk penelitian selanjutnya, dapat mengkaji tentang bagaimana mengetahui suatu modul adalah modul notherian atau bukan, metodenya mungkin melalui media homomorfisma modul juga, atau mungkin menggunakan media yang lain.

\section{DAFTAR PUSTAKA}

[1] Yunita Wildaniati, "Penjumlahan Langsung Pada Modul," Malang, 2009.

[2] Khusniyah, "Kajian Homomorfisme Modul Atas Ring Komutatif," Malang, 2007.

[3] Wijna. (2009, 5 Februari) http://wijna.web.ugm.ac.id.

[4] John R. Durbin, Modern Algebra an Introduction third edition. New York: John Willey \& Sons, Inc, 1992.

[5] M.D Raisinghania and R.S Aggarwal, Modern Algebra. New Delhi: Ram Nagar, 1980.

[6] Achmad Arifin, Aljabar. Bandung: ITB 
Bandung, 2000.

[7] David S Dummit and Richard M. Foote, Abstract Algebra. New York: Prentice-Hall International, Inc, 1991.

[8] Howard Anton, Aljabar Linear Elementer Edisi Kelima. Jakarta: Erlangga, 1987.

[9] M.D Raisinghania and R.S Aggarwal, Modern Algebra. New Delhi: Ram Nagar, 1980.

[10] Anton Howard, Aljabar Linear Elementer Edisi Kelima. Jakarta: Erlangga, 1987. 